\title{
A MEDIAÇÃO CULTURAL EM MEIO A CONTROVÉRSIAS
}

CULTURAL MEDIATION IN BETWEEN CONTROVERSIES

MEDIACIÓN CULTURAL EN EL CONTROVERSIAS

Cayo Honorato ${ }^{1}$ 


\section{Resumo}

Desde o caso Queermuseu, a expectativa de que a tarefa dos programas educativos fosse corrigir a "incompreensão do público" relativamente à arte moderna ou contemporânea foi significativamente questionada. Ocorre que diferentes públicos, baseando-se em valores quase sempre alheios aos pressupostos e debates do mundo da arte, têm se manifestado contrariamente à realização de de-terminadas exposições e trabalhos de arte, com uma veemência e repercussão inauditas. Qual deve ser então o papel da mediação diante dessas rejeições? Neste artigo, recorremos à metodologia proposta por Nathalie Heinich (2010) para uma sociologia dos valores, qual seja, a de "um bom uso da neutralidade", para propor uma reformulação das atribuições e maneiras de fazer da mediação cultural no âmbito da educação em exposições de arte e espaços museais; uma que leve em conta seus aspectos investigativo, documentário, pós-crítico e propriamente político.

Palavras-chave: Mediação cultural; Guerras culturais; Caso Queermuseu.
1 Cayo Honorato é professor adjunto no Departamento de Artes Visuais (VIS) da Universidade de Brasília (UnB), na área de História e Teoria da Educação em Artes Visuais. Doutor em Educação pela FE/USP; mestre em Educação pela FE/UFG; especialista em Arte Contemporânea e bacharel em Artes Visuais pela FAV/UFG. Integra a rede Another Roadmap for Arts Education desde 2015. É pesquisador associado do Centre for the Study of the Networked Image (CSNI) da London South Bank University (LSBU), desde 2018, onde atualmente desenvolve pesquisa de pós-doutorado. cayohonorato.unb@gmail.com Lattes: http://lattes.cnpq.br/8539725380344782.

Orcid: https://orcid.org/0000-0002-5220-0691

\section{Abstract}

Since the Queermuseum case, the expectation that the task of educational programs is to correct the 'audiences' misunderstandings' with respect to modern or contemporary art has been significantly questioned. The point is that different audiences, based on values almost always unrelated to the presuppositions and debates of the art world, have been contrary to the realization of certain exhibi-tions and works of art, with an unprecedented vehemence and repercussion. What, then, is the role of mediation in the face of such rejections? In this article, we use the methodology proposed by Nathalie Heinich (2010) for a sociology of values, that is, "a good use of neutrality", to propose a reformulation of the attributions and ways of doing cultural mediation in the context of education in art exhibitions and museum spaces; one that takes into account its investigative, documentary, post-critical and properly political aspects.

Key-words: Cultural mediation; Culture wars; Queermuseum case. 


\section{Resumen:}

Desde el caso de Queermuseu, la expectativa de que la tarea de los programas educativos sería corregir el "malentendido del público" sobre el arte moderno o contemporáneo ha sido cuestionada significativamente. Resulta que diferentes audiencias, basadas en valores casi siempre ajenos a los supuestos y debates del mundo del arte, se han opuesto a la celebración de ciertas exposiciones y obras de arte, con una vehemencia y repercusión sin precedentes. ¿Cuál debería ser entonces el papel de la mediación ante tales rechazos? En este artículo, recurrimos a la metodología propuesta por Nathalie Heinich (2010) para una sociología de los valores, es decir, "un buen uso de la neutralidad", para proponer una reformulación de las atribuciones y formas de hacer de la mediación cultural en el campo de la educación en museos y exposiciones de arte; una que tenga en cuenta sus aspectos documental, poscríticos, políticos y de investigación.

Palabras-Claves: Mediación cultural; Guerras culturales; Caso Queermuseu. 


\section{Introdução}

Desde o caso Queermuse ${ }^{1}$, a expectativa ainda muito difundida de que a tarefa dos educativos fosse corrigir a "incompreensão do público" relativamente à arte moderna ou contemporânea, ou mesmo lhe proporcionar boas (e brandas) experiências, foi significativamente questionada. Trata-se de uma expectativa unilateral, diga-se de passagem, que considera o público como um simples suporte das ações artísticas e/ou institucionais, em vez de agentes transformadores das próprias instituições. Ocorre que diferentes públicos, baseando-se em princípios e valores quase sempre alheios aos pressupostos e debates da história e do mundo da arte, têm se manifestado contrariamente à realização de determinadas exposições e trabalhos de arte, com uma veemência e repercussão inauditas - o que a mediação cultural não pode negligenciar.

Certamente, o teor dessas manifestações nem sempre corresponde ao caráter conflitivo, em sentido transformador, que Michael Warner (2002, p. 56-63) atribuiu à noção de contrapúblicos. Por vezes, corresponde à ascensão de um tipo de conservadorismo que, nos últimos anos, decidiu tomar parte - conforme seus interesses - das guerras culturais que vêm sendo travadas desde a emergência das políticas identitárias. ${ }^{2}$ Porém, assim como os contra-públicos, tais manifestações questionam aquilo que foi socialmente sancionado, seja por uma ou várias instituições culturais, seja pelas políticas culturais. Ao mesmo tempo, tornam públicos sentimentos que há pouco eram privados, embora muitas vezes de ódio, em um contexto disponível de circulação, por meio do qual podem ser compartilhados, favorecendo a constituição de um público. Em todo caso, tornou-se evidente que a "docilidade do público" - que avalizava aquela expectativa unilateral - não pode mais ser pressuposta.

Desse modo, o que está para ser enfrentado, por parte dos educativos, não é tão somente uma indiferença ou desinteresse relativamente à arte, decorrentes da sua "incompreensão", mas sim uma rejeição combativa, parcialmente organizada, que eventualmente mobiliza certas concepções de arte, e que de qualquer forma tem suas próprias razões, quer estejamos de acordo com elas ou não. Essas mudanças, que podemos caracterizar pela "emergência dos não especialistas", postulam a insuficiência de uma mediação comprometida apenas com a formação de público e a democratização cultural, uma vez que tais objetivos têm como certo um desejo do público pela arte, em geral, por um tipo de arte, cuja importância terá sido cons-

\footnotetext{
1. Em 10 de setembro de 2017, após manifestações de repúdio terem se avolumado pelas redes sociais nos dias anteriores, o Santander Cultural decidiu encerrar a exposição Queermuseu - Cartografias da Diferença na Arte Brasileira, em cartaz na instituição desde o dia 15 de agosto, antecipando seu término em quase um mês. As principais queixas eram de que a exposição - mais precisamente, três ou quatro obras expostas - fazia apologia à pedofilia e zoofilia, além de blasfemar contra símbolos e valores religiosos cristãos. O episó-dio foi sucedido por uma série de outros eventos, em diferentes cidades brasileiras (Campo Grande, Jundiaí, São Paulo, Belo Horizonte, Fortaleza, Vitória, Brasilia), chegando à condução coercitiva do curador da exposi-ção em 08 de novembro, mediante requerimento aprovado pela CPI dos Maus-tratos.

2. Ao menos duas leituras desse fenômeno podem ser exemplificadas aqui: (1) Referindo-se à atuação do Mo-vimento Brasil Livre (MBL) no caso Queermuseu, a jornalista e escritora Eliane Brum (2017) escreve: "Desde então [2010], o corpo de mulheres e de gays, lésbicas, travestis e transexuais tornou-se uma das principais moedas de barganha eleitoral". (2) Entrevistando Kim Kataguiri, um dos líderes do MBL, sobre a mudança de foco da organização, a jornalista Anna Virginia Balloussier (2017) transcreve: "Esse distanciamento [em rela-ção à moral, aos costumes, às tradições], segundo ele [Kataguiri], "levou a uma derrota política acachapante para a direita, porque as pessoas, antes de se preocuparem com o que é economicamente viável, se preocu-pam com o que é justo. A gente esqueceu de focar no discurso da justiça - que o MBL trouxe de volta para o liberalismo e o conservadorismo brasileiros"'.
} 
truída sob condições históricas e sociais particulares. Qual deve ser então o papel da mediação em meio a essas controvérsias?

\section{Desacordos em torno da arte}

Pouco traduzida para o português, ${ }^{3}$ a socióloga francesa Nathalie Heinich (2010) dedicou parte do seu trabalho à pesquisa do que chamou de "rejeições à arte contemporânea". Seu livro originalmente publicado em 1997 reúne seis diferentes estudos de caso, realizados no período de 1985 a 1995, por meio dos quais se dedica à elaboração de uma sociologia dos valores. Embora as recentes guerras culturais tragam um emaranhado de questões que Heinich não precisou enfrentar naquele momento, a autora ainda pode nos oferecer aportes metodológicos para enfrentar controvérsias públicas em torno da arte. Antes disso, da nossa perspectiva, seu mérito estava em considerar como produtivo aquilo (as rejeições) que os educativos tendem a dissimular. De resto, podemos pensar que sua sociologia produz uma espécie de estudo de público, mas não segundo os interesses da fidelização; um no qual os públicos são reconhecidos como sujeitos sociais e praticantes da cultura. Neste artigo, revisaremos um estudo de caso específico, objeto do capítulo VI do livro, intitulado Ping à Paris, 1994: De Beaubourg à Brigitte Bardot (cf. HEINICH, 2010, p. 155-194).

Em novembro de 1994, a exposição Hors limites, realizada no Centro Georges Pompidou em Paris, foi inaugurada sem que um dos trabalhos selecionados fosse apresentado na sua integridade: a instalação intitulada Le Théâtre du Monde (1993), do artista chinês Huang Yong Ping. $O$ trabalho se constituia de uma espécie de viveiro em forma de tartaruga, no qual seriam expostos: serpentes, aranhas, lagartos, escorpiões, lacraias e baratas, alimentados só com água. Segundo Heinich (2010, p. 157 et seq.), a decisão foi tomada na véspera da abertura, após uma rápida e intensa campanha de mobilização dos defensores dos animais. Mais precisamente, depois de uma decisão administrativa da Prefeitura, que observando a legislação vigente recusou o pedido de autorização feito pelo Centro, considerando a "inadequação do ambiente em questão às espécies apresentadas [...], onde não se pode assegurar que elas terão seu território próprio" (p. 161, tradução minha) ${ }^{4}$. Contudo, parte do trabalho foi mantida - o viveiro sem os animais -, acompanhada de uma amostra das cartas de protesto enviadas à instituição, além de um comunicado em resposta, assinado pelo presidente do Centro, pelo diretor do Museu e pelo curador da exposição. Uma "solução de compromisso", que atendia mas não se dobrava aos detratores.

Anos depois, o mesmo trabalho foi objeto de polêmicas semelhantes. Em abril de 2007, em uma retrospectiva do artista na Vancouver Art Gallery, no Canadá, artista e instituição decidiram, 10 dias após a abertura, retirar os animais do trabalho, após pressão da Sociedade para a Prevenção de Crueldade contra Animais. Em se-

\footnotetext{
3. Em 2001, a EDUSC publicou A sociologia de Norbert Elias e, em 2008, A sociologia da arte - ambos esgota-dos. Uma quantidade de artigos avulsos pode ser encontrada em revista acadêmicas brasileiras. O livro a que iremos nos referir teve uma versão em artigo publicada em 2011 na revista Observatório Itaú Cultural (n. 12), com o título "A arte contemporânea exposta às rejeições: contribuição à sociologia dos valores".

4. Todas as citações de fontes em língua estrangeira têm tradução minha.
} 
tembro de 2017, uma petição online denunciando a "crueldade contra os animais em nome da arte", acompanhada de manifestações em frente ao museu, solicitou ao Guggenheim de Nova Iorque que retirasse 3 trabalhos - dentre eles o de Ping - da exposição Art and China after 1989: Theater of the World. A sucessão desses episódios sugere mudanças nas circunstâncias em que tais controvérsias se desdobram, no decorrer dos últimos 20 anos. Ao que parece, as instituições se tornaram mais suscetíveis às pressões externas. Certamente, aumentou a desconfiança em relação a seu papel de legitimadoras sociais e representantes do interesse público. Ao mesmo tempo, na medida em que vão assumindo a lógica do mercado, tornam-se mais dependentes de certa aprovação pública, ou melhor, de seus clientes. Também as disputas em torno das instituições se tornaram mais acirradas, incluindo "ameaças de violência". Finalmente, as pressões por parte dos detratores se midiatizaram. Em 1994, não houve repercussão significativa na imprensa. Em 2017, petições online e boatos virais mobilizam protestos (ou mesmo ataques) presenciais e virtuais.

Para Heinich (2010), os argumentos dos detratores e dos defensores da arte podem ser atribuídos a diferentes "registros de valores". Desse modo, os detratores são principalmente assimilados a um registro ético, empenhado na defesa do bem contra o mal, do justo contra o injusto - no caso em questão, com base em uma sensibilidade ao sofrimento dos animais que se dispõe a denunciar os causadores desse sofrimento -, enquanto os defensores são principalmente assimilados a um registro estético, empenhado na defesa da liberdade de criação artística e que, eventualmente, recorre à tradição artística para se legitimar.

Todavia, a autora observa que os defensores, no caso, prevendo a possibilidade de serem interpretados como insensíveis, inumanos ou cínicos, evitam opor com veemência seus argumentos estéticos aos argumentos éticos dos adversários. Em vez disso - reconhecendo deste modo sua fraqueza relativa -, deslocam tais argumentos para um terceiro registro, que ela chama de hermenêutico, por meio do qual o valor da autonomia criativa cede lugar a um valor de significação e simbolização, que não necessariamente agrada os públicos, mas os convoca para um trabalho de interpretação. Essa "duplicação axiológica" (melhor dizendo: esse empréstimo de credibilidade) entre o estético e o hermenêutico devolve aos defensores alguma capacidade de persuasão diante dos indecisos. No caso, permite-lhes justificar que a obra em questão seria um "símbolo da paz", ou que ela favorece uma "harmonia entre as raças e as culturas" (palavras do curador), apresentando-se desse modo como o exato oposto daquilo que seus detratores lhe imputam.

Convém observar, como sublinha Heinich, que há uma desigualdade de forças entre os diferentes registros, ou ainda, uma hierarquização por ser evidenciada em cada contexto. Embora o registro estético seja avalizado pela instituição, que a princípio parece possuir maior legitimidade social do que os visitantes avulsos, os valores éticos possuem maior capacidade de mobilização, "[...] na medida em que se apoiam em causas bem estabelecidas, dotadas de uma jurisdição e de associações já constituídas, como no caso da defesa dos animais" (HEINICH, 2010, p. 181). Assim, os "efeitos de dominação" de um sobre outro, como a autora faz questão de observar - diferenciando-se aqui de Pierre Bourdieu -, não se baseiam numa cons- 
trução unilateral da relação dominante/dominado, mas sim na interação (dinâmica) de diferentes fatores:

Nem absoluta, nem inexistente, a desigualdade entre os registros de valores [...] deve ser considerada como [...] relativa à natureza do objeto de litígio, às características dos sujeitos que julgam e às propriedades do contexto de enunciação (HEINICH, 2010, p. 189).

Contudo, sua preocupação em compreender (empiricamente) por que os detratores se saíram vitoriosos termina sem relativizar a distribuição de forças que aí se configurou. Faço aqui uma ressalva. Poderíamos acrescentar que o registro estético também é fraco, na medida em que quantitativamente minoritário, ou socialmente supérfluo. Contudo, o gesto de dissidência que muitas vezes se manifesta na "liberdade de criação" - ainda que se possa questioná-lo nas suas ocorrências mais individualistas ou elitistas, isto é, quando ele desconsidera as relações sociais nas quais se constitui - é fonte necessária de uma desconfiança e resistência em relação às arbitrariedades das convenções e poderes sociais. Haveria, portanto, sem prejuízo para a legitimidade relativa de cada registro, efeitos de regulação recíproca por serem considerados entre eles. Afinal de contas, apesar da heterogeneidade dos registros em disputa, todos eles se referem a um mesmo bem, "[...] que podemos resumir como sendo a civilização, a humanidade ou, segundo os termos de Boltanski e Thévenot, a 'comunidade humana'" (HEINICH, 2010, p. 182).

O termo "registro de valor", segundo Heinich, tem a vantagem de poder qualificar tanto as modalidades de ação quanto as de discurso. Mas também, enquanto ferramenta de compreensão, de deslocar as divergências entre uns e outros argumentos, de um simples conflito de gostos ou desacordo sobre valores supostamente compartilhados, para uma eventual "incompreensão total" de parte a parte a respeito daquilo que é valor para o outro. Em suma, a certa altura, detratores e defensores não se referem à mesma "realidade". O termo busca portanto identificar cada contexto de enunciação, aquilo que é valor nesse contexto, assim como as linhas divisórias entre os diferentes sistemas de valores: enquanto os detratores não reconhecem o trabalho como arte, os defensores não consideram que o trabalho pudesse infringir a lei; enquanto a defesa hermenêutica denuncia a incapacidade dos detratores de ampliar o campo do simbólico para além da literalidade material do trabalho, a denúncia ética acusa os defensores de não ampliar o campo da sensibilidade, de não se compadecerem como o sofrimento animal. Assim, "[...] é menos um conflito de valores que assistimos [...] do que um conflito de registro de valores, que desloca o desacordo à montante, na direção de saber se o objeto litigioso é da competência da moral, da arte ou do simbólico" (HEINICH, 2010, p. 184).

Diante desse conflito, os diferentes argumentos podem até ser capazes de persuadir quem ainda não aderiu a nenhum dos lados, mas não quem se encontra entrincheirado no registro adversário: "Compreendemos então que os argumentos de uns e de outros não têm a menor chance de se responderem, e que se a legislação pode momentaneamente suspender a controvérsia, ela não necessariamente a encerra" (HEINICH, 2010, p. 184). Neste ponto, o debate democrático - no sentido de um debate entre diferenças - pode ser prejudicado, não só pela incompreensão 
entre as partes, mas também pela suspensão (formal) da controvérsia. ${ }^{5}$ Assim, mais do que insistir no enquadramento persuasivo do debate, é preciso - caso o restabelecimento do debate democrático seja uma premissa - que cada lado assuma outra estratégia de interação; uma que passe pela tradução de um registro em outro, ou ainda, pela transformação de um registro pelo outro. Eventualmente, um lado parece reconhecer o registro do outro: os defensores podem (eticamente) alegar que os animais estão sendo bem cuidados, assim como os detratores podem (esteticamente) propor, em nome da arte, a destruição performática de certas obras de arte. Porém, fazem-no aí para reafirmar seu próprio registro. Segundo Heinich (2010, p. 184), “[...] é preciso, noutros termos, que um e outro campo aceitem a possível ilegitimidade de sua própria posição, além da possível legitimidade da posição adversária".

\section{Um "bom uso da neutralidade" (pela mediação cultural)}

Retomamos enfim a questão levantada anteriormente: qual deve ser o papel da mediação diante dessas controvérsias? De que modo ela pode favorecer esse tipo de transformação (de um registro pelo outro)? As observações de Heinich, naturalmente, não se referem ao mediador cultural, mas sim ao pesquisador ou, mais particularmente, ao sociólogo dos valores, para quem ela recomenda um "bom uso da neutralidade". De algum modo, no entanto, penso que elas podem ser apropriadas pela mediação cultural. Certamente, a recomendação de que a mediação "seja neutra" parece contrariar os pressupostos de uma mediação crítica, para quem a neutralidade constitui uma posição solidária ao status quo. De fato, ela pode parecer polêmica. Mas não se trata neste caso de se evitar uma posição crítica, deixando prevalecer uma posição hegemônica, e sim, de se evitar uma posição a priori, que de maneira hegemônica tem se comprometido com a defesa da arte, desconsiderando os públicos; como se a arte fosse o único agente da crítica, como se os públicos não pudessem manifestar o heterogêneo. Para que se possa compreender o registro do outro, sem necessariamente pôr-se de acordo com ele, e ao mesmo tempo desdobrar a controvérsia, sem que para reafirmar uma posição prévia, é preciso pensarmos em ações não só em face dos detratores, mas também dos defensores; ações que se situem efetivamente em meio às controvérsias.

Por certo, ao considerar uma variedade de informações, o pesquisador (assim como o mediador) pode ora endossar, ora rechaçar cada um dos lados, sem chegar a uma opinião conclusiva. Para Heinich, no entanto, é justamente essa labilidade de opinião que lhe permite "deslocar-se de um [lado] ao outro, compreender a lógica de um e outro e, eventualmente, fazer com que ela seja compreendida por cada lado" (HEINICH, 2010, p. 190). A neutralidade, nesse sentido, não é uma objetividade em si mesma, mas sim uma "suspensão de julgamento" - o que não sugere subtrair as opiniões para uma esfera privada, mas considerar (publicamente) a pluralidade existente dos regimes de relações à experiência, interagindo uns com os outros. Do mesmo modo, essa neutralidade não recusa engajar-se naquilo que mobiliza os ato-

5. Refiro-me aos efeitos da decisão administrativa da Prefeitura, no caso estudado por Heinich. Mas talvez um interesse pelo desdobramento (em vez da suspensão formal) da controvérsia possa diferenciar a "mediação em meio a controvérsias" da simples mediação de conflitos. 
res; diferentemente da manifestação de uma posição - eventualmente valorizada como "um imperativo viril" -, a neutralidade é o que permite ao pesquisador - especialmente quando o debate atingiu certa inércia - "produzir um máximo de efeitos sobre o real", ao permitir "que [uma opinião] seja entendida por todos e, correlativamente, que uns sejam (em alguma medida) entendidos por outros" (HEINICH, 2010, p. 191). Assim, ela terá contribuído para que as próprias condições do debate democrático sejam restabelecidas.

Portanto, não se trata de restabelecer "o mito da neutralidade científica". Noutros termos, não se trata de alcançar a verdade mais verdadeira, supostamente "independente dos sistemas sociais e econômicos", arrogando-se desse modo uma posição superior aos fatos e à realidade; mas de se abrir à consideração simultânea de uma variedade de verdades, na forma como elas são verdades para si mesmas, "banhadas por uma inegável atmosfera sócio-político-cultural" (JAPIASSU, 1975, p. 9-10). Nesse sentido, continua Heinich, a neutralidade não é uma realidade em si, mas um objetivo metodológico a ser alcançado: "Não se trata, noutros termos, de 'acreditar' em uma linguagem da neutralidade, mas de constituí-la da forma mais rigorosa possível" (HEINICH, 2010, p. 192). Essa suspensão (profissional) de julga-mento, é acompanhada por uma postura descritiva, que em vez de se pronunciar (normativamente) sobre a legitimidade dos valores em disputa, busca explicitar os sistemas de valores utilizados pelos atores, pronunciando-se (descritivamente) sobre a forma como sua legitimidade é construída. Heinich argumenta que o papel do pesquisador não é decidir se determinado trabalho é ou não é cruel - inclusive porque os atores já fazem isso com abundância, por vezes com muita propriedade. Em vez disso, seu papel é "compreender os processos de ativação de certas ações, assim como as reações que elas provocam. [...] Noutros termos, o sociólogo [dos valores] não deve substituir-se aos atores" (HEINICH, 2010, p. 192-193). ${ }^{6}$

Podemos inclusive observar que uma política - algo em relação a que ela se mobiliza histórica e socialmente - é implícita a essa neutralidade. Ser neutro, nesse sentido, não é ser isento. Embora Heinich não tenha exatamente descrito transformações deste tipo, a transformação de um registro pelo outro, sem reduzir o outro ao mesmo, ou ainda, aquilo que Agamben (2009, p. 92) chamou de "partilha sem objeto", são momentos de um debate efetivamente democrático, no qual as diferenças (e as identidades) estão abertas à possibilidade de se diferenciarem de si mesmas; assim como à possibilidade de construírem um mundo (dissensualmente) comum. Eis o que o método parece implicitamente aspirar, para o que poderia ser empregado. Não sabemos ainda se a autora sustenta, a respeito da democracia, uma perspectiva consensual ou "agonística" (MOUFFE, 2005), que nos pareceria mais consequente. Nos limites do que ela propõe, o que o sociólogo pode aportar, para além do que os atores já sabem e fazem, é "uma capacidade de refazer o laço entre as partes opostas, de restabelecer as zonas de comunicação, de fazer entender, para além dos argumentos, as razões de uns e de outros" (HEINICH, 2010, p. 194). 


\section{Mediando o caso Queermuseu}

Entre o caso estudado por Heinich e o caso Queermuseu, não há só uma distância temporal (entre 1994 e 2017) e cultural (entre França e Brasil) - que já nos pediria considerar inúmeras mediações. A significativa popularização do acesso à Internet - providenciando uma circulação incomensurável de conteúdos expressivos -, assim como o ressurgimento das guerras culturais (na forma como revertem pautas morais em projetos políticos) - em um ambiente de "debate" marcado pela disseminabilidade de fake news e boatos virais -, produziram um amálgama entre público e privado que mal começamos a compreender. Não é possível listar aqui por falta de espaço, mas também pela dificuldade de esgotá-las - todas as questões que permeiam essa controvérsia. Nesse emaranhado, chamam a atenção a mencionada reconfiguração dos contrapúblicos em sentido hegemônico, mas também a persistente autorreferencialidade dos defensores. Portanto, se acaso cabe mais aos defensores do que aos detratores restabelecer o debate democrático, torna-se oportuno perguntar: quando os primeiros se deixam transformar pelos segundos?

Embora não se possa afirmar que a onda de manifestações a partir do caso Queermuseu tenha sido iniciada pela militância do Movimento Brasil Livre (MBL), é certo que a atuação do grupo fez dele o principal polo de referência dos detratores (cf. TAVARES \& AMORIM, 2017). Em debate promovido pelo programa Esfera Pública da Rádio Guaíba, dois dias após o encerramento da exposição, Paula Cassol (in: CURADOR [...], 2017a), coordenadora regional do MBL em Porto Alegre, resumiu algumas das posições da organização: eles são - a seu modo - favoráveis à liberdade de expressão, ${ }^{7}$ assim como à prerrogativa das famílias na educação de seus filhos, além de contrários ao financiamento público da produção cultural, particularmente via Lei Rouanet. Eis o que disse Cassol: "[...] as pessoas têm o direito de se sentirem ofendidas com aquilo [a exposição] e de não quererem que seus filhos tenham acesso a isso e, muito menos, que a gente tenha que pagar com dinheiro público uma exposição dessas" (in: CURADOR [...], 2017a). A posição articula um direito privado (sobre os filhos) com uma contestação pública (que tem contornos de prática cívica). Desse modo, entendem que as reações não configuram censura, mas sim boicote.

Dentre os defensores, de um modo geral, os argumentos são de que houve censura. Para Rodrigo Cássio de Oliveira (in: BRANDALISE, 2017), doutor em estética e professor da UFG, "há diferença entre não gostar e pedir para que não seja exibida [...]. Exigir o fim da exposição é intolerância". Noutra entrevista, o professor é taxativo: "O resultado de toda essa polêmica e da decisão final [o fechamento da exposição] foi censura. Não foi simplesmente um boicote" (in: MENDONÇA, 2017). Do mesmo modo, Luiz Camillo Osorio (in: D'ANGELO, 2017), curador da exposição em que o artista Wagner Schwartz apresentou a performance La Bête, afirmou que "fechar uma exposição por conta de protestos sobre o conteúdo das obras é um ato extremo e uma forma de censura". Segundo Paula Alzugaray (2017), editora e crítica de arte, o episódio tem uma significação histórica: "Ainda que reações ultraconser-

7. $O$ entendimento (ou as divergências) a respeito do que seja liberdade de expressão, fundamental ao debate sobre a diferença entre censura e boicote, foi uma das principais controvérsias do caso Queermuseu. 
vadoras não sejam exceção no Brasil, este foi o primeiro caso de censura consumada a uma exposição". Por sua vez, Francisco Alambert (in: BRANDALISE, 2017), professor de história da arte da USP, sugerindo uma explicação, entende que o episódio foi "uma tragédia sintomática da época de obscurantismo, conservadorismo histérico e violência que estamos passando".

$\mathrm{Na}$ verdade, os argumentos dos defensores foram mais diversos. Dentre eles, alguns nos remetem às categorias identificadas por Heinich. Há argumentos que recorrem à tradição artística, como o de Eliseu Venturi (2017), mestre em direitos humanos, para quem, "fosse este o foco (pornografia), [...] veríamos que a sexualidade perpassa representações realmente antigas, como parecem atestar, além da arte rupestre, a arte greco-romana". Assim como argumentos de autoridade, como este de Paula Alzugaray (2017), para quem o Santander Cultural chancelou a opinião de que Cena do interior II (1994), de Adriana Varejão, faz apologia à zoofilia, "ignorando o caráter crítico ao colonialismo da obra dessa artista, aspecto vastamente estudado por pesquisadores do estatuto da antropóloga Lilia Moritz Schwarcz" (grifo meu). Além de argumentos hermenêuticos, como este de Venturi (2017), para quem "A arte não impõe seu conteúdo [...]: ela manifesta objetos que demandam compreensão e cuja mensagem é dada à discussão, à discordância, ao incômodo, à fruição, ao gozo".

Neste ponto, no entanto, dificilmente se pode cogitar uma compreensão entre as partes. Parte dos argumentos hermenêuticos não funciona como defesa, mas sim como contra-ataques que buscam desqualificar o adversário, acusando-o de desinformação, falta de cultura, incapacidade cognitiva ou má-fé. Assim, para o crítico de arte Moacir dos Anjos (2017), "Não se pode atribuir à performance [La Bête], muito menos à produção artística em geral, aquilo que lhes foi imputado sem uma análise e discussão sérias e informadas sobre o que se passou na ocasião". Do mesmo modo, para a advogada Juliana Campos (in: ALZUGARAY, 2017), "Isso é desinformação compartilhada e viralizada. Muitas pessoas contrárias à mostra sequer se abriram à discussão, mesmo diante de comprovações de que não havia nenhuma ilegalidade nas obras". Outros são ainda mais irônicos: para o cineasta e produtor Felipe Poroger (2017), "Os escândalos inauguraram [...] um terceiro modelo de apreciação artística - este um verdadeiro milagre: não se faz mais necessário sequer entrar no museu para julgar o seu conteúdo; basta chegar à fachada com cartazes difamatórios". Todos esses argumentos, no entanto, partilham da ideia de que é a arte que precisa de compreensão, não suas rejeições.

Certamente, dentre os argumentos dos defensores, alguns deveriam ser discutidos seriamente pelos detratores, uma vez que operam num "mesmo" registro ético, ainda que, em parte, revertendo-o em favor de uma sensibilidade artística. Ao questionar a criminalização das produções artísticas, que segundo ela "movimentam a economia e criam possibilidades", a artista Adriana Varejão (in: GOBBI, 2017) adverte: "Enquanto isso, crianças estão expostas a riscos reais de abusos enquanto estão soltas nas ruas, nas cidades que estes prefeitos [Marcelo Crivella e João Doria] administram". Por sua vez, Moacir dos Anjos (2017) se refere ao fato de que a imagem de um menino de 11 anos, encontrado na cela de uma cadeia em Altos, no Piauí, junto a um homem acusado de pedofilia e estupro de menor, repercutiu 
muito menos nas redes sociais - o equivalente a somente $8,2 \%$ do número de compartilhamentos, nos dois primeiros dias de circulação - do que a imagem do performer nu sendo tocado na mão e no pé por uma criança em uma exposição de arte. De modo semelhante a Varejão, porém menos preocupada com a defesa da arte em primeira instância, Eliane Brum (2017) chega a relativizar o prejuízo causado à Queermuseu, em termos de cerceamento da liberdade de expressão, para enfatizar outros apagamentos que esse tipo de ataque pode ajudar a produzir e perpetuar: "Ao denunciar a arte e os artistas como 'pedófilos', o que se produz é o apagamento de um fato bastante incômodo: o de que a maioria das crianças violadas é violada por familiares e conhecidos".

Todavia, como sugeriu Eliane Brum (2017), "De nada adianta chamar as pessoas que se manifestaram contra a mostra de 'ignorantes', 'fascistas' e 'nazistas'. É também preciso escutá-los para além do óbvio. E para além do que é dado a ver". Do mesmo modo, ela insiste em que não seria o caso desqualificá-los por não compreender o que é arte: "Se parte significativa da população não teve e não tem acesso à arte é também porque os privilégios se mantêm intactos neste país graças a muita gente que entende de arte" (BRUM, 2017). De fato, boa parte dos defensores não se desloca dos próprios registros; observam uma falta de abertura à discussão, mas não se abre ela própria à discussão. Em contraponto à posição de Gaudêncio Fidelis, curador da Queermuseu, para quem a mostra tinha um "alto teor acadêmico", com obras que estiveram nas "mais importantes exposições desse país", e que tinha a "disposição de abrir o debate para essas discussões [sobre diversidade, respeito à diferença, questões de gênero, de identidade]", o youtuber Arthur do Val (in: CURADOR [...], 2017a), ligado ao MBL, rebateu: "Não tenho realmente esse nível pra debater com um curador especialista em arte. Uma coisa que ele falou é que ele respeita muito as diferenças, que a exposição é pra abrir o debate. A questão é: o que se faz depois que se abre o debate?"

Pode haver um "cinismo competente" nessa pergunta, mas ela atinge em cheio o argumento de Fidelis. Note-se que do Do Val não só ironiza o "teor acadêmico" da exposição, como refuta as credenciais para se tomar parte num debate especializado, perguntando pela disposição da mostra para considerar como diferenças as posições que assumem rejeitá-la. Em debate promovido pelo programa Café com Jornal da TV Band em 15 de setembro de 2017, o youtuber acrescentou: "Não faz sentido que um artista queira que as pessoas entendam exatamente aquilo que ele quis dizer com aquela obra. Faz parte da liberdade de expressão das pessoas falar algo contra aquilo com que se sentiram ofendidas" (in: CURADOR [...], 2017b). Neste ponto, por exemplo - que não deve ser considerado isoladamente -, talvez os defensores pudessem reconhecer a razão dos detratores, mesmo que isso não seja suficiente para "refazer o laço entre as partes opostas".

\section{Algumas considerações}

De qualquer forma, a ideia de que a mediação cultural pudesse praticar aquela neutralidade - como forma de desdobrar as controvérsias, buscando restabelecer o debate democrático - teria implicações "deontológicas", relativas à caracterização 
conceitual e profissional dessa atividade. A primeira delas seria pensá-la como um espaço de pesquisa e produção de conhecimento, em vez de simples ferramenta de reprodução de uma experiência consumada noutro lugar (pelas curadorias, por exemplo). A segunda, como uma atividade que assume uma postura descritiva ou documentária, em vez de exclusivamente interventiva, no sentido de fazer prevalecer uma agenda previamente acordada, sem que muitas vezes seus destinatários tenham participado desse acordo. A terceira seria pensá-la como uma mediação pós-crítica, que não se substitui aos atores, mas que sobretudo considera aquilo que é produzido empiricamente pelos atores, em contraponto àquilo que apenas se sustenta teórica e discursivamente. Tudo isso, por certo, excede a tarefa educacional tipicamente atribuída à mediação, que tem na convocação feita pelo registro hermenêutico - para o trabalho da interpretação das obras de arte pelos públicos - uma de suas principais formulações. Em última análise, convoca a mediação para tomar lugar em meio a processos e debates políticos e culturais mais amplos, nos ela quais teria uma significação própria.

Obviamente, nada disso pressupõe que tal ideia pudesse ser facilmente implementada. Por exemplo, ela precisaria contrariar a "notável regularidade empírica" verificada por Cass Sunstein (1999), de que o debate tende a mover os indivíduos e grupos para posições mais extremas do que aquelas que eles sustentavam anteriormente - o que ele irá chamar de "polarização de grupo". Inicialmente, segundo o autor, a polarização não se refere ao que acontece entre grupos, mas ao que ocorre dentro de um grupo, discutindo um caso ou problema. Todavia, se um grupo assume uma posição mais extrema, em comparação a uma posição anterior sua, pode ser que o faça para se diferenciar ainda mais de outro grupo. O ponto é que a vontade de ser transformado pelo debate democrático não pode ser pressuposta. O que poderia nos alargar, ampliar nossa consciência, parece de algum modo ser recebido como ameaça. Chegamos, desse modo, a um novo patamar do que são os desafios da mediação. Em todo caso, como sugere Sunstein:

[...] a melhor resposta para esse problema é tentar evitar uma balcanização e fragmentação sociais, por meio de mecanismos que assegurem uma "esfera pública" usada por pessoas com perspectivas concorrentes, tanto a respeito dos fatos, quanto dos valores. Se uma esfera pública geral se encontra indisponível ou impraticável, torna-se ainda mais importante assegurar que, no decurso de um processo deliberativo, as pessoas sejam expostas a uma gama de visões razoáveis em conflito. (SUNSTEIN, 1999, p. 30)

\section{Referências}

AGAMBEN, Giorgio. O amigo. In: O que é o contemporâneo? e outros ensaios; tradução de Vinícius Nicastro Honesko. Chapecó: Argos, 2009, p. 77-92.

ALZUGARAY, Paula. Onde o debate acontece. Revista Select. São Paulo, 23 set. 2017. Disponível em <http://bit.ly/2AyCSzm>. Acesso em 22 jun. 2018.

ANJOS, Moacir dos. Por uma pedagogia do olhar. Revista Zum. São Paulo, 30 out. 
2017. Disponivel em <https://bit.ly/2Fpbx4s>. Acesso em 22 jun. 2018.

BALLOUSSIER, Anna Virginia. Moral e costume entram em foco em congresso do MBL. Jornal Folha de São Paulo. São Paulo, 11 nov. 2017. Disponível em <http://bit. ly/2hmRDOI>. Acesso em 21 jun. 2018.

BRANDALISE, Camila. Arte é arte. Revista Isto É, n. 2492. São Paulo, 15 set. 2017. Disponivel em <http://bit.ly/2i2mRuu>. Acesso em 22 jun. 2018.

BRUM, Eliane. Gays e crianças como moeda eleitoral. Jornal El País. São Paulo, 18 set. 2017. Disponível em <http://bit.ly/2xTglPG>. Acesso em 21 jun. 2018.

CURADOR DA QUEERMUSEU E MBL DISCUTEM EXPOSIÇÃO. Programa Esfera Pública. Porto Alegre: Rádio Guaíba, 12 set. 2017 [2017a]. Programa de rádio (1h29m). Disponível em <http://bit.ly/2jdkbxS>. Acesso em 22 jun. 2018.

CURADOR E YOUTUBER DEBATEM SOBRE EXPOSIÇÃO QUEERMUSEU. Programa Café com Jornal. São Paulo: TV Band, 15 set. 2017 [2017b]. Programa de TV (19m11s). Disponivel em <http://bit.ly/2AuYYUa>. Acesso em 22 jun. 2018.

D'ANGELO, Helô. Casos como o 'Queermuseu' devem ser tratados como desafios educacionais, diz crítico de arte. Revista Cult. São Paulo, 11 set. 2017. Disponível em $<$ http://bit.ly/2ywOvGt>. Acesso em 22 jun. 2018.

GOBBI, Nelson. Artistas vão processar políticos por difamação. Jornal O Globo. Rio de Janeiro, 06 out. 2017. Disponível em <https://glo.bo/2fQurqH>. Acesso em 22 jun. 2018.

HEINICH, Nathalie. L'art contemporain exposés aux rejets. Paris: Fayard; Pluriel, 2010.

JAPIASSU, Hilton. O mito da neutralidade científica. Rio de Janeiro: Imago, 1975.

MENDONÇA, Heloísa. Caso Queermuseu mostra que são tempos de intolerância. Da direita, mas também da esquerda. Jornal El País. São Paulo, 14 set. 2017. Disponível em <http://bit.ly/2zQ6AUi>. Acesso em 22 jun. 2018.

MOUFFE, Chantal. Por um modelo agonístico de democracia. Revista de Sociologia e Politica, Curitiba, no 25, p. 11-23, nov. 2005. Disponível em <http://bit.ly/2JZ8yTz>. Acesso em 19 jun. 2018.

POROGER, Felipe. Da selfie à intolerância: o brasileiro agora se preocupa com a arte? Revista Carta Capital. São Paulo, 04 out. 2017. Disponível em <https://bit.ly/2JB3DaZ>. Acesso em 22 jun. 2018. 
SUNSTEIN, Cass. The Law of Group Polarization. John M. Olin Program in Law and Economics Working Paper no 91, 1999. Disponível em: <http://bit.ly/2K4XHuB>. Acesso em 19 jun. 2018.

TAVARES, Flavia \& AMORIM, Daniele. Como movimentos conservadores conseguiram encerrar a exposição Queermuseu. Revista Época. São Paulo, 15 set. 2017. Disponível em <https://glo.bo/2ABhxX0>. Acesso em 22 jun. 2018.

VENTURI, Eliseu. Em uma democracia, a arte possui plena liberdade e apoio de provocar. Revista Carta Capital, Blog Justificando. São Paulo, 02 out. 2017. Disponível em <https://bit.ly/2kieG0G>. Acesso em 22 jun. 2018.

WARNER, Michael. Publics and counterpublics. 3aㅡ reimp. New York: Zone Books, 2002. 